\title{
Should We Resect and Discard Low Risk Diminutive Colon Polyps
}

\author{
Pujan Kandel and Michael B. Wallace \\ Department of Gastroenterology and Hepatology, Mayo Clinic Florida, Jacksonville, FL, USA
}

Diminutive colorectal polyps $<5 \mathrm{~mm}$ are very common and almost universally benign. The current strategy of resection with histological confirmation of all colorectal polyps is costly and may increase the risk of colonoscopy. Accurate, optical diagnosis without histology can be achieved with currently available endoscopic technologies. The American Society of Gastrointestinal Endoscopy Preservation and Incorporation of Valuable endoscopic Innovations supports strategies for optical diagnosis of small non neoplastic polyps as long as two criteria are met. For hyperplastic appearing polyps $<5 \mathrm{~mm}$ in recto-sigmoid colon, the negative predictive value should be at least $90 \%$. For diminutive low grade adenomatous appearing polyps, a resect and discard strategy should be sufficiently accurate such that post-polypectomy surveillance recommendations based on the optical diagnosis, agree with a histologically diagnosis at least $90 \%$ of the time. Although the resect and discard as well as diagnose and leave behind approach has major benefits with regard to both safety and cost, it has yet to be used widely in practice. To fully implement such as strategy, there is a need for better-quality training, quality assurance, and patient acceptance. In the article, we will review the current state of the science on optical diagnose of colorectal polyps and its implications for colonoscopy practice. Clin Endosc 2019;52:239-246

Key Words: Colorectal polyps

\section{INTRODUCTION}

Colorectal cancer is the second most cause of cancer related death in United States and majority of cancer arise from benign adenomas. ${ }^{1}$ Colonoscopy offers real-time management of benign adenomas to break adenoma- carcinoma sequence, thus decreasing the possibility of colorectal cancer development. Polypectomy reduce the occurrence of colorectal cancer by approximately $50 \%$ in long term follow up. ${ }^{2}$ More than $90 \%$ of the colorectal polyps are small $(6-9 \mathrm{~mm})$ or smaller $(<5 \mathrm{~mm})^{3}$ and half of the them are non-neoplastic, ${ }^{4}$ only $1.7 \%$ of cases have advanced histology (villous or dysplasia) with lower possibility of developing colon cancer. ${ }^{3,5}$ Therefore

Received: July 23, 2018 Accepted: September 4, 2018

Correspondence: Michael B. Wallace

Department of Gastroenterology and Hepatology, Mayo Clinic Florida, 4500 San Pablo Road, Jacksonville, FL 32224, USA

Tel: +1-904-953-6982, Fax: +1-904-953-7260, E-mail: wallace.michael@mayo.edu ORCID: https://orcid.org/0000-0002-6446-5785

cc This is an Open Access article distributed under the terms of the Creative Commons Attribution Non-Commercial License (http://creativecommons.org/ licenses/by-nc/3.0) which permits unrestricted non-commercial use, distribution, and reproduction in any medium, provided the original work is properly cited. many polypectomies add unnecessary risk during colonoscopy. Current standard of care is to resect most polyps and sent for histology. ${ }^{6,7}$ The ability to diagnose polyp histology in real-time during colonoscopy would allow leaving recto-sigmoid hyperplastic polyps (diagnose and leave) and resecting small adenomas without sending for formal histology (resect and discard). As cancer progression in small polyps is remarkably rare, we believe enhanced imaging technology may guide proper treatment decision at real-time during colonoscopy.

\section{DIMINUTIVE COLORECTAL POLYPS: OPTICAL DIAGNOSIS}

Optical diagnosis is a concept in which histopathology of colorectal polyps is determined at the time of colonoscopy by imaging technologies such as high definition white light (HDWL), narrow band imaging (NBI), or other narrow spectrum imaging technologies. This approach has potential benefits in terms of cost-effectiveness and efficiency of colorectal screening by decreasing the procedure time, costs associated with histology, and complications. ${ }^{8,9}$ The American 
Society of Gastrointestinal Endoscopy (ASGE) established the Preservation and Incorporation of Valuable endoscopic Innovations (PIVI) process with regard to leaving recto-sigmoid hyperplastic polyps without resection as well as a resect and discard approach for small adenomas. A survey results from American College of Gastroenterology reported inconsistency in diminutive colorectal polyps management. ${ }^{10}$ Most gastroenterologists (78\%) reported that they leave small colorectal polyps in an average-high risk individual, but interestingly they leave them in a certain scenarios like advanced age, patients on anticoagulation, and appearance of polyps as non-adenomatous histology. In addition, gastroenterologists with greater experience and those confident to differentiate polyps' morphology diagnose and leave diminutive colorectal polyps in place. In another multicenter cross-sectional study, a survey was conducted at three university centers in Europe and Australia in which patient's inclination to accept resection of small colorectal polyps was studied. The main objective of the study was to measure the proportions of patients wishing to partake in a randomized trial that accede resection of small colorectal polyps. Results from this study showed that 50\% participants were interested to participate in a clinical trial in which differing of resection of diminutive colorectal polyps would be applied (95\% confidence interval [CI], 46\%-55\%) and $57 \%$ of partakers would be affable to accepting resection of diminutive colorectal polyps (95\% CI, 51\%-63\%) outside of clinical trial. Factors associated for deferring diminutive colorectal polyp resection were higher education $(p=0.001)$, more information on cancer risk ( $p=0.002)$, and the lower insight of cancer risk (all $p<0.001){ }^{11}$ This was the first study to examine patient perspective whether they would be interested to defer resection of diminutive colorectal polyps while undergoing a colonoscopy. Results from this study also demonstrated that $50 \%$ would agree to not taking out of small colorectal polyps when the benefits and harm of this approach was provided. Note, that this included leaving diminutive adenomas in situ which is more expansive the current ASGE PIVI process of only leaving recto sigmoid hyperplastic polyps in situ. Published studies have shown that the risk of finding cancer in cross-sectional colonoscopy is about 1 per 2,000-3,000 polyps. ${ }^{3,5,12,13}$ Regarding the progression of diminutive adenomas to cancer, it is likely that the latency phase is lengthier than the total life expectancy of the individuals in majority of cases. Studies have also demonstrated that most adenomas including non-diminutive adenomas appearing before the age of 65 rarely progress to cancer and merely $50 \%$ progress to size $>10$ $\mathrm{mm}$ in individual's life span. ${ }^{14-16}$

The PIVI guideline on evaluation of histopathology of diminutive polyps was developed by the ASGE to provide guidance on appropriate use of optical diagnosis. This strategy potentially has very large economic benefit. Based on simulated Markov modeling regarding "resect-and-discard" strategy of detected diminutive colorectal polyps, the economic benefit was $\$ 25$ per person screened colonoscopy, but when projected to US population would result in annual savings of $\$ 33$ million. ${ }^{9}$ When the cost associated with "diagnose-and-leave" strategy is applied, in which each polypectomy cost approximately $\$ 179$ per person, which would convert to the estimated stashes of $\$ 1$ billion per year to the US health care system. This approach also has additional benefit by avoiding unnecessary adverse events related to polypectomy of small polyps.

To set guidelines for diminutive colorectal polyps management, the ASGE has developed a novel initiation in 2011 called PIVI. The main goals of PIVI initiative are to resolve important clinical questions and to establish diagnostic, and/ or therapeutic inceptions for endoscopic skills and technologies. The main objective is to aid right integration of endoscopic skills and tools to optimize patient outcome. Thus, the ASGE has developed a PIVI threshold for optical diagnosis of diminutive colorectal polyps:

"1. For a technology to be used to guide the decision to leave suspected recto-sigmoid hyperplastic polyps $5 \mathrm{~mm}$ or smaller in place (without resection), the technology should provide a $90 \%$ or greater negative predictive value (NPV) (when used with high confidence) for adenomatous histology.

2. For colorectal polyps $5 \mathrm{~mm}$ or smaller to be resected and discarded without pathologic assessment, endoscopic technology (when used with high confidence) used to determine histology of these polyps, when combined with the histopathologic assessment of polyps larger than 5 $\mathrm{mm}$, should provide $90 \%$ or greater agreement in assignment of post-polypectomy surveillance intervals when compared with decisions based on pathology assessment of all identified polyps. ${ }^{13}$

\section{IMAGING TECHNOLOGIES FOR OPTICAL DIAGNOSIS HIGH DEFINITION WHITE LIGHT COLONOSCOPY}

HDWL colonoscopy has been utilized to distinguish polyp histology at the time of colonoscopy and on still images. However, HDWL has low accuracy in distinguishing neoplastic vs non-neoplastic colorectal polyps ${ }^{17-20}$ with an accuracy of only 59\%-84\%. Diagnostic values of HDWL for optical diagnosis of polyp histology (Table 1). ${ }^{18-25}$ 


\section{Chromoendoscopy}

This technique was first utilized in Japan to describe histopathology of colorectal polyps at the time of colonoscopy. This technique provides the colonic pit patterns (Kudo pit pattern) and is widely used classification: ${ }^{26}$ Kudo pit patterns 1 and 2 indicate $=$ non-neoplastic lesion whereas Kudo 3 s, $3 \mathrm{~L}$ and 4 are considered as neoplastic lesion and Kudo 5 represents submucosal invasion. Kudo classification is precise in optical diagnosis $(85 \%-96 \%)^{19,20,27-29}$ when used with high definition colonoscope and chromoendoscopy. However, this technique needs additional training, equipment, time, and considerable learning curve. ${ }^{30}$ Diagnostics value of Chromoendoscopy for optical diagnosis of polyp histology (Table 2)..$^{19-21,23,29,31}$

\section{Narrow spectrum technologies}

For last few years, several technologies are available for visualization of diminutive colorectal polyps that are better than HDWL. These imaging technologies include i-SCAN (Pentax, Mississauga, Canada), Fujinon Intelligent Color Enhancement
(FICE; Fujinon Inc., Wayne, NJ, USA), and Narrow band imaging (NBI; Olympus, Tokyo, Japan), with a push button technologies integrated into the colonoscope. They are easy to use, quick, and user friendly.

\section{Narrow band imaging}

NBI (Olympus) is also called virtual chromoendoscopy with a narrow-band with "blue light" that has the capability to provide mucosal detail and vascular structures. ${ }^{32-35}$ Adenomatous tissue is categorized by augmented angiogenesis, and appears as browner when visualized with NBI. The NBI International Colorectal Endoscopic (NICE) is the validated classification system for the categorization of diminutive colonic polyps (Table 3). ${ }^{36}$

Results of meta-analyses (by ASGE technology committee systematic review and meta-analyses) of NBI studies evaluating colorectal polyps histology in real-time, the pooled NPV for adenomatous histology was $91 \%(95 \% \mathrm{CI}, 88-94)^{13}$ and on high confidence the pooled NPV was 93\% (95\% CI, 90-96).

Table 1. Diagnostic Values for Optical Diagnosis of Colorectal Polyps with High Definition White Light Colonoscopy

\begin{tabular}{lcccc}
\hline Study & Number of polys & Size $(\mathbf{m m})$ (mean), (range) & Sensitivity (\%) & Accuracy (\%) \\
\hline Apel et al. $(2006)^{18}$ & 273 & 3.0 & 93.0 & 81.0 \\
De Palma et al. $(2006)^{20}$ & 240 & $3.0-4.0$ & 91.0 & 76.0 \\
Su et al. $(2006)^{22}$ & 110 & - & 83.0 & 82.0 \\
Tischendorf et al. $(2007)^{19}$ & 100 & $11(2-50)$ & 63.0 & 59.0 \\
Chiu et al. $(2007)^{23}$ & 180 & $5(2-20)$ & $62.0-65.0$ & $67.0-68.0$ \\
Ignjatovic et al. $(2011)^{24}$ & 80 & 4.0 & 69.0 & 64.0 \\
Longcroft-Wheaton et al. $(2011)^{25}$ & 232 & $5(2-9)$ & 75.0 & 71.0 \\
\hline
\end{tabular}

Table 2. Diagnostic Values for Optical Diagnosis of Colorectal Polyps with Chromoendoscopy

\begin{tabular}{lcccc}
\hline Study & Number of polys & Size $(\mathbf{m m})$ (mean), (range) & Sensitivity (\%) & Accuracy (\%) \\
\hline Kato et al. $(2006)^{31}$ & 3,438 & $>5$ & 98.0 & 75.0 \\
Togashi et al. $(2006)^{29}$ & 923 & $1-11$ & 92.0 & 88.0 \\
De Palma et al. $(2006)^{20}$ & 240 & $3-4$ & 94.0 & 95.0 \\
Tischendorf et al. $(2007)^{19}$ & 100 & $11(2-50)$ & 90.0 & 91.0 \\
Chiu et al. $(2007)^{23}$ & 180 & $5(2-20)$ & $74.0-90.0$ & $91.0-92.0$ \\
\hline
\end{tabular}

Table 3. The NBI International Colorectal Endoscopic Classification

\begin{tabular}{lll}
\hline \multicolumn{2}{c}{ NBI classification of polyp } \\
\hline Characteristics & \multicolumn{1}{c}{ Hyperplastic polyp } & Adenoma \\
\hline Color & Lighter than surrounding mucosa & Brown relative to surrounding mucosa \\
Vessels & Solitary blood vessel passing through polyp or none & Dense surrounding blood vessels \\
Surface pattern & White spots of same size & Tubular structure encircled by brown blood vessels \\
\hline
\end{tabular}

NBI, narrow band imaging. 
On subgroup analysis, there was no significant difference was observed when compared to academic (91.8\%, 95\% CI, 89-94) versus community centers (88.3\%, 95\% CI, 82-94). In addition novice endoscopist reached PIVI threshold with high confidence (90\%, 95\% CI, 86-94) where has expert endoscopist exceeded PIVI threshold when assessment was done with high confidence (95\%, 95\% CI, 92-98) (Figs. 1, 2). ${ }^{13}$

In addition, regarding the post-polypectomy surveillance intervals based on NBI optical biopsy versus histopathology, the percentage of agreement was $89 \%$ (95\% CI, 85-93). On subgroup analysis, higher agreement was observed at academic medical centers $91 \%$ (95\% CI, 86-95) compared to community settings $82 \%$ (95\% CI, 74-90), higher agreement with experts 92\% (95\% CI, 88-96) compared to novice endoscopist $82 \%$ (82\%, 95\% CI, 75-88), and higher agreement with high confidence diagnosis $91 \%$ (95\% CI, 88-95) compared to no confidence level provided 79\% (95\% CI, 71-86). In addition, on high confidence diagnosis, expert exceeded PIVI thresholds $93 \%$ (95\% CI, 90-96) compared to novice operators $87 \%$ (95\% CI, 82-93). ${ }^{13}$

In one retrospective study, real-time optical diagnosis predicted accurate surveillance interval in 92.7\% (95\% CI, 91.496.2) and optical diagnosis was not determined only in $0.3 \%$ (4/1254). The NPV for diagnosis of adenoma from all polyps was $86.8 \%$ (95\% CI, 82.9-90.0), but when restricted to recto-sigmoid region only, NPV was increased to $95.4 \%$ (95\% CI, 91.8-97.7) achieving both the PIVI thresholds. ${ }^{37}$ On subgroup analyses looking at the cost savings with resect and discard policy, the highest savings were achieved for all diminutive polyps saving $\$ 309$ per patient by reducing histopathology assessment of all polyps.

In addition, published studies have reported NBI has simi-

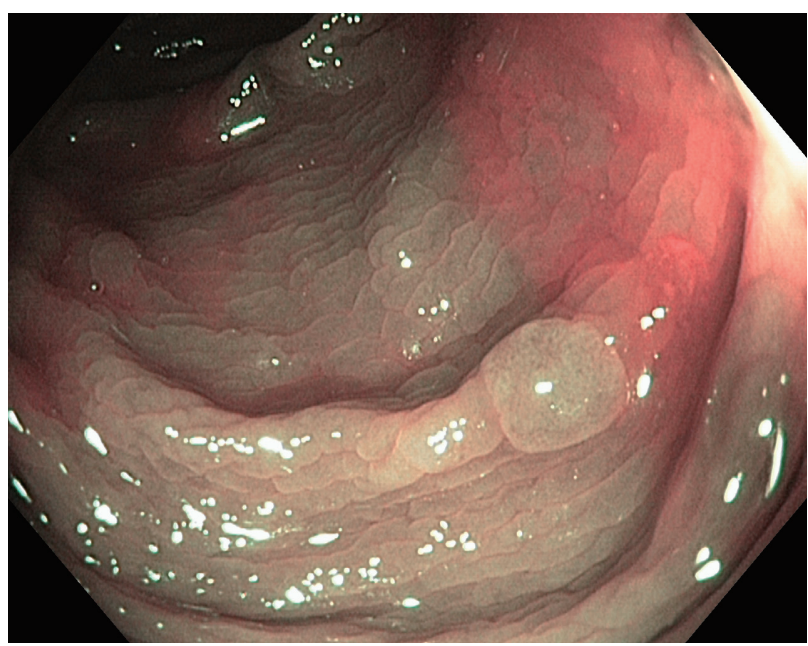

Fig. 1. Colonoscopy image of hyperplastic polyp with narrow band imaging Features include lighter color than surrounding mucosa, black dot pattern, and absence of vessels. lar sensitivity (92\%-94\%) and specificity (86\%-88\%) to chromoendoscopy when assessed by experienced endoscopist in academic medical centers centers. ${ }^{17,19,21-2,2,27,38-41}$

\section{i-SCAN}

Meta-analyses (by ASGE technology committee systematic review and meta-analyses) of 8 studies evaluating the diminutive colorectal polyps using i-SCAN were compared to histology. The pooled NPV was 84\% (95\% CI, 76-91). On subgroup analysis, NPV for experienced endoscopist was 96\% (95\% CI, 94-98) compared to $72 \%$ (95\% CI, 69-76) for novice endoscopist. ${ }^{13}$ Regarding the level of agreement with histopathology for post-polypectomy surveillance (based on Multi Society Task Force post-polypectomy surveillance intervals), only one i-SCAN study assessed the post-polypectomy surveillance. Result from this study demonstrated an agreement of $69.5 \%$ (95\% CI, 63-75) and PIVI threshold was not met. ${ }^{42}$

\section{Fujinon intelligent color enhancement}

Meta-analyses (by ASGE technology committee systematic review and meta-analyses) of 8 studies evaluating the optical diagnosis using FICE scan and were compared to histopathology. Results showed that the pooled NPV was $80 \%$ (95\% CI, 76-85). On subgroup analyses, NPV of FICE was not improved with endoscopist experience but FICE performance was improved with the use of magnification with NPV of $85 \%$ (95\% CI, 79-91). ${ }^{13}$ Thus PIVI threshold was not met with this technology for optical biopsy.

Regarding the post-polypectomy surveillance intervals, only 2 FICE studies have been published. ${ }^{25,43}$ Based on the two studies, agreement in assigning post-polypectomy surveillance intervals was 100\% (95\% CI, 91-100) and 97\% (95\% CI, 89-100).

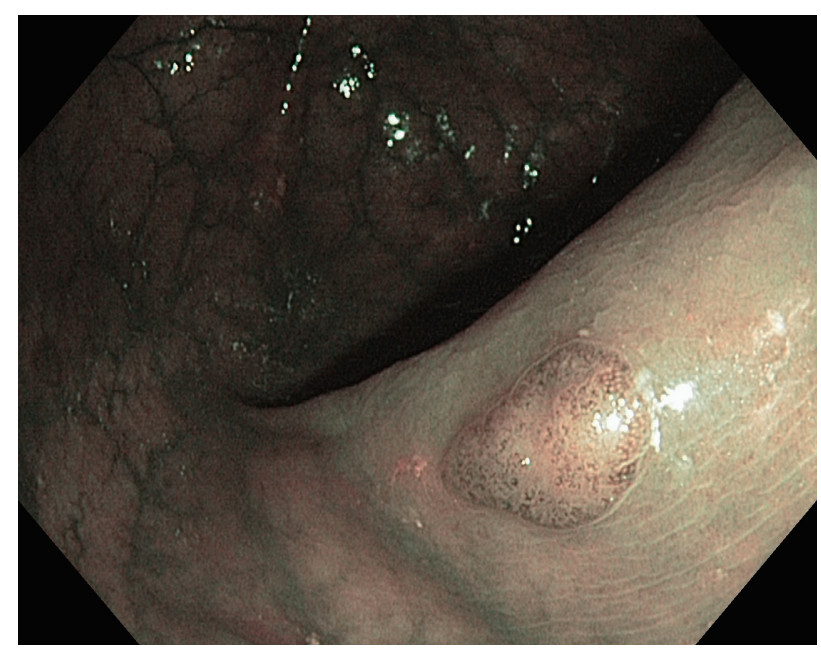

Fig. 2. Colonoscopy image of adenomatous polyp with narrow band imaging. Features include overall dense brown color, thick brown vessels surrounding tubular, oval and variable- shaped white mucosa. 


\section{ARTIFICIAL INTELLIGENCE AND BLUE LIGHT IMAGING IN COLORECTAL POLYP CHARACTERIZATION}

Optical diagnosis using NBI in non-academic setting is below the ASGE PIVI threshold. ${ }^{44}$ To overcome this drawback, artificial intelligence (AI) based diagnosis of colorectal polyp has been brought into the field of gastroenterology for polyp detection. ${ }^{45-50}$ In one study AI based diagnosis using deep neural network-computer aided detection (DNN-CAD) was used to evaluate the NBI images of small colorectal polyps (Neoplastic or hyperplastic). Results from this study showed that DNN-CAD system accurately classified polyp histology with a positive predictive value of $89.6 \%$ and a NPV of $91.5 \%$ at a shorter time interval than the expert endoscopist, ${ }^{51}$ and less than half of novice endoscopist categorized polyps with a NPV of $90 \%$. Thus, this automated diagnostic system could be the potent aide for gastroenterologists provided good NBI images. In another study effectiveness of CAD software for colorectal lesions was evaluated using magnifying NBI images. The NPV of neoplastic lesions was $95.6 \% .^{52}$ The concordance between CAD and experienced endoscopist for optical diagnosis was $90.9 \%$. Results from this study showed a fairly high categorization rate with CAD with magnifying NBI images and were not significantly different from those of experienced gastroenterologists. Although CAD has the potential to bring significant change in the field of endoscopy in future, endoscopists will not be substituted by CAD as they are the key person to correctly recognize suitable images for machine to learn. However, computers may simplify colonoscopy performance and help in prevention of colorectal cancer incidence and mortality.

Advanced endoscopic imaging technologies have made a significant improvement in colorectal polyp characterization. Currently only the NICE classification is used solely for the NBI technology $y^{52}$ and is not reproducible when different technology is used. ${ }^{53}$ In one study blue-light imaging (with or without magnification) was used to create a new classification for distinguishing colorectal polyps (hyperplastic, adenomatous, and invasive malignant lesions). ${ }^{54}$ Blue light imaging is selectively absorbed by hemoglobin and is based on the direct emanation of blue (without filter) light with shorter wavelength (410 nm). Magnification with zoom is up to $\times 135$. On the basis of modified Delphi process, endoscopists created 12 factors into 3 main domains (that included morphological and pit/vessel findings) such as: (1) Polyp surface (mucus, yes/ no; regular/irregular; [pseudo] depressed, yes/no), (2) Pit appearance (featureless, yes/no; round/non-round with/without dark spots homogeneous/heterogeneous distribution with/ without focal loss), (3) Vessels (present/absent, lacy, peri-cryp- tal, and irregular). ${ }^{54}$

1. Interobserver agreement for polyp surfaces each domain as follows:

A) For the polyp surface domain for mucus: 0.92 with and 0.88 without magnification): Perfect

B) Polyp surface domain for the regular/irregular surface: 0.67 with and 0.66 without magnification): Substantial

2. Interobserver agreement for polyp pit pattern:

A) Pit pattern: 10.9 with and 0.8 without magnification: Good

B) Pit pattern round/non-round features: 0.77 with and 0.69 without magnification, but less reliable for the homogeneity of distribution: with/without optical magnification $0.58 .^{54}$

3. Interobserver agreement for the vessel $(0.81-0.85):^{54}$ Perfect

A) Although blue light imaging technology looks promising in detection of colorectal lesions, however future studies are needed to validate this classification and potential application in clinical practice.

\section{BARRIERS TO IMPLEMENTATION}

Cost efficiency is a hot topic in the field of gastroenterology. Current strategies for management of colorectal polyps recommend that all identified polyps be removed and the reimbursement to endoscopist is based on therapeutic procedures performed and pathological analysis of polyps. If resect and discard strategy is applied this may impact the reimbursement in an environment where physicians are compensated extra for polypectomy and also some group of gastroenterologists which own or share in the revenue of pathology services. It is important to note that resection of hyperplastic polyps adds unnecessary costs for resection and pathological evaluation where malignant transformation is exceedingly rare. In the other hand, the resect and discard strategy is only recommended by endoscopists when there is agreement of $>90 \%$ between the optical diagnosis and pathological assessment of polyps which may be applicable in academic centers only. ${ }^{13}$ Therefore, AI based CAD may help in accurately diagnosing colorectal polyps to avoid inappropriate resection, and, further, may help in saving cost associated with pathological evaluation and potential applicability in community settings too. ${ }^{51}$

Another important concern is not resecting diminutive 
polyps may interfere the measurement of adenoma detection which is one of the quality metrics in colonoscopy. One landmark study showed the proportional decrease in risk of colorectal cancer with increase in adenoma detection ( $1 \%$ increase in adenoma detection rate (ADR) is associated with a $3 \%$ decrease in the risk of colon cancer). ${ }^{55}$ Endoscopists who have high ADRs are those who identify and remove all the smallest of polyps. This indicates that removing all visible polyps prevents from cancer. However it is still unclear whether resection of all polyps that is preventive, or it is simply a consideration of more comprehensive mucosal inspection for major lesions. ${ }^{56}$ Thus, the best alternative could be calculation of ADR based on optical diagnosis although this is more subject to gaming.

Another aspect to address is the patient anxiety after proposing the concept of diminutive polyp deferral. In one cross sectional survey, an assessment of patient approval of optical diagnosis and their answers was conducted. ${ }^{57}$ In this study, $49.6 \%$ patients backed diagnose and leave strategy and $60.8 \%$ supported resect and discard strategy. However, only $41.7 \%$ of patients supported both the strategies. Factors related to refusal of resection and discard were missed cancer diagnosis in family (odds ratio, $0.59 ; p=0.03$ ), and bowel cancer history (either personal or in family) (odds ratio, $0.7 ; p=0.4$ ). Results also showed that patients who didn't support resect and discard strategy were more likely to ask compensation if a mistake occurred. ${ }^{57}$ In another cross-sectional survey study on outpatient's colonoscopy, factors regarding the acceptance of resect and discard were evaluated. Results showed that younger, white and ambulatory surgery center patients were more prone to agree the resect and discard strategy. Patients who declined "resect and discard" were more prone to be agreeable to pay more amount of out-of- for pathological evaluation of diminutive polyps ( $97.1 \%$ vs. $44.5 \%) .^{58}$ Thus, although optical diagnosis is lucrative for healthcare economy, this approach is still not assuring and quite variable from patient perspectives.

Leaving polyps may also cause anxiety to patient and thus may need to provide adequate information to patient on both the risk and benefit of this approach. Further studies are needed to measure and improve patient acceptance of the optical diagnosis before widespread use in clinical practice.

\section{CONCLUSIONS}

The improvement in endoscopic imaging technologies has increased our ability to detect colorectal polyps, including very small, low risk lesions. While there are clearly benefits to higher adenoma detection and resection, the resection and pathological analysis of such a low risk lesions has increased the cost and risks of colonoscopy procedure. The correct assessment of diminutive polyps at real time would allow accurate decision making either to resect or discard for small adenomas without sending for pathological analysis or to leave recto-sigmoid hyperplastic polyps with negligible risk.

Based on PIVI guideline, for "diagnose-and-leave" approach for optical diagnosis of small recto-sigmoid polyps, the NPV be $90 \%$ or higher with high confidence. Results from the meta-analysis, the ASGE technology committee concluded that NBI meets the PIVI threshold and supports a "diagnose-and-leave" strategy for predicting neoplastic polyps in the recto-sigmoid colon.

For a "resect-and-discard" approach for $5 \mathrm{~mm}$ or smaller adenomas and when combined with histopathological analysis of polyps larger than $5 \mathrm{~mm}$, the meta-analyses demonstrated that NBI exceeded $90 \%$ or higher agreement for post-polypectomy surveillance intervals with high confidence (91\%) in academic centers and experienced endoscopists. Thus, NBI imaging modality can be used for "resect-and discard" strategy for $5 \mathrm{~mm}$ or smaller colorectal adenomas.

Although PIVI has developed a threshold for resect-and-discard policy for optical diagnosis of diminutive colorectal polyps, the implementation still poses challenges such as widespread application of this approach in community practice, establishing the standard for the use of tools and skills among endoscopists, and the development of quality assurance program.

\section{Conflicts of Interest}

Michael B. Wallace reports consulting income from Olympus Corp and grant support from Boston Scientific and Cosmo pharmaceuticals. Other author has no financial conflicts of interest.

\section{REFERENCES}

1. Morson B. President's address. The polyp-cancer sequence in the large bowel. Proc R Soc Med 1974;67(6 Pt 1):451-457.

2. Zauber AG, Winawer SJ, O'Brien MJ, et al. Colonoscopic polypectomy and long-term prevention of colorectal-cancer deaths. N Engl J Med 2012;366:687-696.

3. Lieberman D, Moravec M, Holub J, Michaels L, Eisen G. Polyp size and advanced histology in patients undergoing colonoscopy screening: implications for CT colonography. Gastroenterology 2008;135:1100-1105.

4. Rex DK, Overhiser AJ, Chen SC, Cummings OW, Ulbright TM. Estimation of impact of American College of Radiology recommendations on CT colonography reporting for resection of high-risk adenoma findings. Am J Gastroenterol 2009;104:149-153.

5. Butterly LF, Chase MP, Pohl H, Fiarman GS. Prevalence of clinically important histology in small adenomas. Clin Gastroenterol Hepatol 2006;4:343-348

6. Lieberman DA, Weiss DG, Harford WV, et al. Five-year colon surveillance after screening colonoscopy. Gastroenterology 2007;133:1077-1085.

7. Levin B, Lieberman DA, McFarland B, et al. Screening and surveillance for the early detection of colorectal cancer and adenomatous polyps, 
2008: a joint guideline from the American Cancer Society, the US Multi-Society Task Force on Colorectal Cancer, and the American College of Radiology. Gastroenterology 2008;134:1570-1595.

8. Kessler WR, Imperiale TF, Klein RW, Wielage RC, Rex DK. A quantitative assessment of the risks and cost savings of forgoing histologic examination of diminutive polyps. Endoscopy 2011;43:683-691.

9. Hassan C, Pickhardt PJ, Rex DK. A resect and discard strategy would improve cost-effectiveness of colorectal cancer screening. Clin Gastroenterol Hepatol 2010;8:865-869, 869.el-e3.

10. Gellad ZF, Voils CI, Lin L, Provenzale D. Clinical practice variation in the management of diminutive colorectal polyps: results of a national survey of gastroenterologists. Am J Gastroenterol 2013;108:873-878.

11. von Renteln D, Bouin M, Barkun AN, et al. Patients' willingness to defer resection of diminutive polyps: results of a multicenter survey. Endoscopy 2018;50:221-229.

12. Ponugoti PL, Cummings OW, Rex DK. Risk of cancer in small and diminutive colorectal polyps. Dig Liver Dis 2017;49:34-37.

13. ASGE Technology Committee, Abu Dayyeh BK, Thosani N, et al. ASGE Technology Committee systematic review and meta-analysis assessing the ASGE PIVI thresholds for adopting real-time endoscopic assessment of the histology of diminutive colorectal polyps. Gastrointest Endosc 2015;81:502.e1-e502.e16.

14. Brenner H, Altenhofen L, Stock C, Hoffmeister M. Natural history of colorectal adenomas: birth cohort analysis among 3.6 million participants of screening colonoscopy. Cancer Epidemiol Biomarkers Prev 2013;22:1043-1051.

15. Mizuno K, Suzuki Y, Takeuchi M, Kobayashi M, Aoyagi Y. Natural history of diminutive colorectal polyps: long-term prospective observation by colonoscopy. Dig Endosc 2014;26 Suppl 2:84-89.

16. Hofstad B, Vatn MH, Andersen SN, et al. Growth of colorectal polyps: redetection and evaluation of unresected polyps for a period of three years. Gut 1996;39:449-456.

17. Machida H, Sano Y, Hamamoto Y, et al. Narrow-band imaging in the diagnosis of colorectal mucosal lesions: a pilot study. Endoscopy 2004;36:1094-1098.

18. Apel D, Jakobs R, Schilling D, et al. Accuracy of high-resolution chromoendoscopy in prediction of histologic findings in diminutive lesions of the rectosigmoid. Gastrointest Endosc 2006;63:824-828.

19. Tischendorf JJ, Wasmuth HE, Koch A, Hecker H, Trautwein C, Winograd R. Value of magnifying chromoendoscopy and narrow band imaging (NBI) in classifying colorectal polyps: a prospective controlled study. Endoscopy 2007;39:1092-1096.

20. De Palma GD, Rega M, Masone S, et al. Conventional colonoscopy and magnified chromoendoscopy for the endoscopic histological prediction of diminutive colorectal polyps: a single operator study. World J Gastroenterol 2006;12:2402-2405.

21. Wilson AI, Saunders BP. New paradigms in polypectomy: resect and discard, diagnose and disregard. Gastrointest Endosc Clin N Am 2015;25:287-302.

22. Su MY, Hsu CM, Ho YP, Chen PC, Lin CJ, Chiu CT. Comparative study of conventional colonoscopy, chromoendoscopy, and narrow-band imaging systems in differential diagnosis of neoplastic and nonneoplastic colonic polyps. Am J Gastroenterol 2006;101:2711-2716.

23. Chiu HM, Chang CY, Chen CC, et al. A prospective comparative study of narrow-band imaging, chromoendoscopy, and conventional colonoscopy in the diagnosis of colorectal neoplasia. Gut 2007;56:373-379.

24. Ignjatovic A, East JE, Guenther T, et al. What is the most reliable imaging modality for small colonic polyp characterization? Study of white-light, autofluorescence, and narrow-band imaging. Endoscopy 2011;43:94-99.

25. Longcroft-Wheaton GR, Higgins B, Bhandari P. Flexible spectral imaging color enhancement and indigo carmine in neoplasia diagnosis during colonoscopy: a large prospective UK series. Eur J Gastroenterol Hepatol 2011;23:903-911.

26. Kudo S, Tamura S, Nakajima T, Yamano H, Kusaka H, Watanabe H.
Diagnosis of colorectal tumorous lesions by magnifying endoscopy. Gastrointest Endosc 1996;44:8-14.

27. Fu KI, Sano Y, Kato S, et al. Chromoendoscopy using indigo carmine dye spraying with magnifying observation is the most reliable method for differential diagnosis between non-neoplastic and neoplastic colorectal lesions: a prospective study. Endoscopy 2004;36:1089-1093.

28. Konishi K, Kaneko K, Kurahashi T, et al. A comparison of magnifying and nonmagnifying colonoscopy for diagnosis of colorectal polyps: a prospective study. Gastrointest Endosc 2003;57:48-53.

29. Togashi K, Konishi F. Magnification chromo-colonoscopy. ANZ J Surg 2006;76:1101-1105.

30. Togashi K, Konishi F, Ishizuka T, Sato T, Senba S, Kanazawa K. Efficacy of magnifying endoscopy in the differential diagnosis of neoplastic and non-neoplastic polyps of the large bowel. Dis Colon Rectum 1999;42:1602-1608.

31. Kato S, Fu KI, Sano Y, et al. Magnifying colonoscopy as a non-biopsy technique for differential diagnosis of non-neoplastic and neoplastic lesions. World J Gastroenterol 2006;12:1416-1420.

32. East JE, Suzuki N, Saunders BP. Comparison of magnified pit pattern interpretation with narrow band imaging versus chromoendoscopy for diminutive colonic polyps: a pilot study. Gastrointest Endosc 2007;66:310-316.

33. Konerding MA, Fait E, Gaumann A. 3D microvascular architecture of pre-cancerous lesions and invasive carcinomas of the colon. Br J Cancer 2001;84:1354-1362.

34. Sano Y, Ikematsu H, Fu KI, et al. Meshed capillary vessels by use of narrow-band imaging for differential diagnosis of small colorectal polyps. Gastrointest Endosc 2009;69:278-283.

35. Hirata M, Tanaka S, Oka S, et al. Evaluation of microvessels in colorectal tumors by narrow band imaging magnification. Gastrointest Endosc 2007;66:945-952.

36. Hewett DG, Kaltenbach T, Sano Y, et al. Validation of a simple classification system for endoscopic diagnosis of small colorectal polyps using narrow-band imaging. Gastroenterology 2012;143:599-607.e1.

37. Gupta N, Bansal A, Rao D, et al. Accuracy of in vivo optical diagnosis of colon polyp histology by narrow-band imaging in predicting colonoscopy surveillance intervals. Gastrointest Endosc 2012;75:494-502.

38. East JE, Suzuki N, Bassett P, et al. Narrow band imaging with magnification for the characterization of small and diminutive colonic polyps: pit pattern and vascular pattern intensity. Endoscopy 2008;40:811-817.

39. Hirata M, Tanaka S, Oka S, et al. Magnifying endoscopy with narrow band imaging for diagnosis of colorectal tumors. Gastrointest Endosc 2007;65:988-995.

40. van den Broek FJ, Reitsma JB, Curvers WL, Fockens P, Dekker E. Systematic review of narrow-band imaging for the detection and differentiation of neoplastic and nonneoplastic lesions in the colon (with videos). Gastrointest Endosc 2009;69:124-135.

41. East JE, Tan EK, Bergman JJ, Saunders BP, Tekkis PP. Meta-analysis: narrow band imaging for lesion characterization in the colon, oesophagus, duodenal ampulla and lung. Aliment Pharmacol Ther 2008;28:854867.

42. Schachschal G, Mayr M, Treszl A, et al. Endoscopic versus histological characterisation of polyps during screening colonoscopy. Gut 2014;63:458-465.

43. Longcroft-Wheaton G, Brown J, Cowlishaw D, Higgins B, Bhandari P. High-definition vs. standard-definition colonoscopy in the characterization of small colonic polyps: results from a randomized trial. Endoscopy 2012;44:905-910.

44. Ladabaum U, Fioritto A, Mitani A, et al. Real-time optical biopsy of colon polyps with narrow band imaging in community practice does not yet meet key thresholds for clinical decisions. Gastroenterology 2013;144:81-91.

45. Kominami Y, Yoshida S, Tanaka S, et al. Computer-aided diagnosis of colorectal polyp histology by using a real-time image recognition system and narrow-band imaging magnifying colonoscopy. Gastrointest 
Endosc 2016;83:643-649.

46. Misawa M, Kudo SE, Mori Y, et al. Characterization of colorectal lesions using a computer-aided diagnostic system for narrow-band imaging endocytoscopy. Gastroenterology 2016;150:1531-1532.e3.

47. McKenna MT, Wang S, Nguyen TB, Burns JE, Petrick N, Summers RM. Strategies for improved interpretation of computer-aided detections for CT colonography utilizing distributed human intelligence. Med Image Anal 2012;16:1280-1292.

48. Tulum G, Bolat B, Osman O. A CAD of fully automated colonic polyp detection for contrasted and non-contrasted CT scans. Int J Comput Assist Radiol Surg 2017;12:627-644.

49. Byrne MF, Chapados N, Soudan F, et al. Real-time differentiation of adenomatous and hyperplastic diminutive colorectal polyps during analysis of unaltered videos of standard colonoscopy using a deep learning model. Gut 2019;68:94-100

50. Nagata K, Endo S, Honda T, et al. Accuracy of CT colonography for detection of polypoid and nonpolypoid neoplasia by gastroenterologists and radiologists: a nationwide multicenter study in Japan. Am J Gastroenterol 2017;112:163-171.

51. Chen PJ, Lin MC, Lai MJ, Lin JC, Lu HH, Tseng VS. Accurate classification of diminutive colorectal polyps using computer-aided analysis. Gastroenterology 2018;154:568-575.
52. Tamai N, Saito Y, Sakamoto T, et al. Effectiveness of computer-aided diagnosis of colorectal lesions using novel software for magnifying narrow-band imaging: a pilot study. Endosc Int Open 2017;5:E690-E694.

53. Repici A, Ciscato C, Correale L, et al. Narrow-band imaging international colorectal endoscopic classification to predict polyp histology: REDEFINE study (with videos). Gastrointest Endosc 2016;84:479-486. e3.

54. Bisschops R, Hassan C, Bhandari P, et al. BASIC (BLI Adenoma Serrated International Classification) classification for colorectal polyp characterization with blue light imaging. Endoscopy 2018;50:211-220.

55. Corley DA, Jensen CD, Marks AR, et al. Adenoma detection rate and risk of colorectal cancer and death. N Engl J Med 2014;370:1298-1306.

56. Bird-Lieberman E, East JE. Diminutive polyps and future colorectal cancer risk perception: how low do we need to go? Endoscopy 2018;50:197-199.

57. Sakata S, Lee AHS, Kheir AO, et al. Patient acceptance of the optical diagnosis and misdiagnosis of diminutive colorectal polyps. Gastrointest Endosc 2017;86:372-375.e2.

58. Rex DK, Patel NJ, Vemulapalli KC. A survey of patient acceptance of resect and discard for diminutive polyps. Gastrointest Endosc 2015;82:376-380.e1 